\title{
The Performance of the Kernel Regression Model for Assessing the Impact of Money Supply on Industrial Growth in Nigeria
}

\author{
Uka C. O. ${ }^{1}$, Osuji G. A. ${ }^{2}$ and Aronu C. O. ${ }^{3}$ \\ ${ }^{1}$ Department of Statistics, Federal College of Agriculture, Ishiagu, Ebony State, Nigeria \\ ${ }^{2}$ Department of Statistics, Nnamdi Azikiwe University, Awka, Nigeria \\ ${ }^{3}$ Department of Statistics, Chukwuemeka Odumegwu Ojukwu University, Anambra State
}

Nigeria

\begin{abstract}
This study examined the performance of the kernel model over the linear regression model for a real-life application in Nigeria. The linear regression and kernel regression model was used to assess the impact of the volume of money supply in Nigeria on industrial growth in Nigeria. The source of data for this study was the secondary source of data collection. Findings showed that there exist a weak positive coefficient of determination measure between volume of money supply and industrial growth which implies that the volume of money weakly explains the total amount of variation in industrial growth using the linear regression model while the kernel model found a strong positive coefficient of determination value which implies that the kernel model was adequate and far better than the linear model for estimating industrial growth in Nigeria. Also, it was found that volume of the money supply does not impact significantly on industrial growth in Nigeria using the linear model while it was found that volume of money impacts significantly on industrial growth using the kernel model. Further findings showed that the residual standard error value for the smoothed model is relatively more efficient than that of the linear model which was attributed to the performance of the kernel regression model.
\end{abstract}

Keywords: Coefficient of Determination, Industrial growth, Kernel model, Linear model, Volume of money supply.

\subsection{INTRODUCTION}

Over the past decade, researcher in applied mathematics and econometrics has shown keen interest on studies relating to how industrial output(s) affect the economy of most countries especially developing economies (Obioma et al., 2015). Very few countries have been able to grow and accumulate wealth without investing in their industries, and a strong and successful manufacturing sector usually precipitates industrialization. The industrial sector has been widely considered to be ideal to drive Africa's development. This is due to the labor-intensive, export- focused nature of the industrial sector of any economy. There exist a direct correlation between exportation levels and the economic success of a country. By increasingly adding value to products before they are sold, revenues are boosted, thereby raising average earnings per input. Industrial development involves the application of modern technology, equipment's and machineries for the production of goods and services, alleviating human suffering and to ensure continuous improvement in their welfare. Industrialization has come to be regarded as a crucial and powerful engine in the overall development process. The World Bank has classified Nigeria as inward oriented by trade orientation. Using data for 1963 - 73 and 1973 - 1985, Nigeria was deemed moderately inward oriented for the production period 1963 - 1973, but strongly inward oriented for the period 1973 - 1985. Since 2001, Nigeria has enjoyed a long period of sustained expansion of the non-oil economy, with growth occurring across all sectors of the economy and accelerating at about $7 \%$. This growth rate increased to about $8-9 \%$ in 2003 despite the financial crisis. This has more than doubled the growth rate in the country prior to 1999. Even in the wake of the global financial crisis in 2009, Nigeria's growth performance fell only to about 4.5 percent.

The aim of this study is assess the performance of the Kernel regression model for estimating the impact of money supply on and industrial growth in Nigeria. 


\subsection{LITERATURE REVIEW}

According to Fashola (2004), modern industrial activities are characterized by high technological innovations, the development of managerial and entrepreneurial talents and improvement in technical skills which normally promote productivity and better living conditions. In recognition of this, successive governments in Nigeria have continued to articulate policy measures and programme to achieve industrial growth and development.

Dauda (2006) stated that if the country's industrial aspirations are to achieve the provision of adequate finance should be accorded high priority. But regrettably, Nigerian industrialists have been badly starved of this very important ingredient for both the establishment and maintenance of industries and could be evidently seen in the following areas; inadequate initial capital for startup, inadequate funds for maintaining existing industries, insufficient funds for expansion. The lack of funds and enabling environment for industrialists has greatly denied the nation the capacity of achieving significant industrial growth or industrialization which Nigeria has always hoped and craved for. He added that the quest to determine to what extent that industrial development have contributed to our economic growth should be paramount.

Hamison (2009) reports the existence of divergence between the growth of real earnings and productivity in the US and Canada, but this result is obtained largely from rising earnings inequality (i.e. increases in the top one per cent of the income distribution alongside stagnant or falling income shares elsewhere). There are also, important measurement issues affecting the observed decline in labour earnings, such as when taking account of the depreciation of fixed assets, which has increased as a result of adoption of new technologies, and which has tended to push the labour share downwards.

Mishel and Shierholz (2011) describe a widening gap between growth rates of productivity and wages (and labour compensation, including bonus payments). Labour compensation growth was particularly low in the private sector, while the growth of average wages was particularly weak for college educated public sector workers.

\subsection{MATERIALS AND METHOD}

\subsection{Source of Data}

The source of data for the study was secondary source of data collection obtained from the Central Bank of Nigeria Statistical Bulletin 2016. The obtained data comprises of annual data on volume of money supply and industrial gross domestic product.

\subsection{Kernel Regression Analysis}

The kernel regression is a non-parametric technique in statistics to estimate the conditional expectation of a random variable. The main objective is to find a non-linear relation between a pair of random variables $\mathrm{X}$ and $\mathrm{Y}$.

The aim of the non-parametric regression model is to estimate the functional relation between $\mathrm{Y}$ and $\mathrm{X}$. This implies that the conditional expectation of a variable $\mathrm{Y}$ relative to a variable $\mathrm{X}$ can be expressed as

$$
\mathrm{E}(Y \mid X)=m(X)
$$

Where, $m$ is an unknown function to be estimated

The relationship in a kernel model can be modeled as:

$$
\mathrm{Y}_{\mathrm{i}}=\mathrm{m}\left(\mathrm{x}_{\mathrm{i}}\right)+\varepsilon_{\mathrm{i}}, \quad \mathrm{i}=1, \cdots, \mathrm{N}, \forall \mathrm{E}\left(\varepsilon_{\mathrm{i}}\right)=0
$$

Note that $: \mathrm{m}(\cdot)=\mathrm{E}[\mathrm{y} \mid \mathrm{x}] \quad$ if $\mathrm{E}\left(\varepsilon_{\mathrm{i}} \mid \mathrm{x}\right)=0$

\subsection{Kernel Smoothing Techniques}


A conceptually simple approach to represent the weight sequence in the local averaging method is to represent the weights distribution by a density function which contains a scale parameter that adjust the size and the form of the weights according to the location of the point with respect to the point of estimation x (Nadaraya, 1964). This density function is known as the kernel function $\mathrm{k}$. smoothing techniques based on this kind of weight representation are called kernel smoothing. The kernel estimate $\mathrm{m}(\mathrm{x})$, is defined as a weighted average of the response variable in a fixed neighborhood around $\mathrm{x}$, determined in shape by the kernel function $\mathrm{k}$ and bandwidth $\mathrm{h}$. The kernel used in this study is the Nadaraya-Watson estimator.

\subsubsection{The Nadaraya-Watson estimator}

The Nadaraya-Watson estimator estimates the kernel $\mathrm{m}(\mathrm{x})$ whichis extracted with a bandwidth $\mathrm{h}$ and expressed as

$$
m\left(x_{i}\right)=n^{-1} \sum_{i=1}^{n} W_{h i}(x) Y_{i}
$$

The weight sequence is written as

$$
W_{h i}(x)=\frac{k_{h\left(x-x_{i}\right)}}{f_{h(x)}}
$$

where,

$$
f_{h}(x)=n^{-1} \sum_{i=1}^{n} K_{h}\left(x-X_{i}\right)
$$

and in which

$K_{h}(u)=\frac{1}{h} K\left(\frac{u}{h}\right)$ is the kernel with scale factor $h$

$m(x)=\frac{n^{-1} \sum_{i=1}^{n} K_{h}\left(x-X_{i}\right) Y_{i}}{n^{-1} \sum_{1=1}^{n} K_{h}\left(x-X_{i}\right)}$ is proposed by Nadaraya (1964) and Watson (1964) and often called the Nadaraya-Watson estimator.

$$
m(x)=\frac{\sum_{i=1}^{n} K_{h}\left(x-X_{i}\right) Y_{i}}{\sum_{i=1}^{n} K_{h}\left(x-X_{i}\right)}
$$

The shape of the kernel weights is determined by the kernel function $\mathrm{k}$ with the smoothing parameter $\mathrm{h}$, which is called the bandwidth. The kernel function is a continuous, bounded and symmetric real function which integrates to one.

Different types of kernel exist and some of them were presented with their properties in table 1.

\section{Table 1: Different Kernel and their properties}

\begin{tabular}{|l|l|l|l|l|}
\hline $\mathrm{S} / \mathrm{N}$ & Kernel & Equation & $\mathrm{R}_{\mathrm{k}}$ & $\mathrm{d}_{\mathrm{k}}$ \\
\hline 1 & Uniform & $\mathrm{K}_{0}(\mathrm{u})=\frac{1}{2} \mathrm{I}(|\mathrm{u}| \leq 1)$ & $1 / 2$ & $1 / 3$ \\
\hline 2 & Epanechnikov & $\mathrm{K}_{1}(\mathrm{u})=\frac{3}{4}\left(1-\mathrm{u}^{2}\right) \mathrm{I}(|\mathrm{u}| \leq 1)$ & $3 / 5$ & $1 / 5$ \\
\hline 3 & Biweight (Quadratic) & $\mathrm{K}_{2}(\mathrm{u})=\frac{15}{16}\left(1-\mathrm{u}^{2}\right)^{2} \mathrm{I}(|\mathrm{u}| \leq 1)$ & $5 / 7$ & $1 / 7$ \\
\hline 4 & Triweight (Tricube) & $\mathrm{K}_{3}(\mathrm{u})=\frac{35}{32}\left(1-\mathrm{u}^{2}\right)^{3} \mathrm{I}(|\mathrm{u}| \leq 1)$ & $350 / 429$ & $1 / 9$ \\
\hline 5 & Gaussian & $\mathrm{K}(\mathrm{u})=\frac{1}{\sqrt{2 \pi}} \exp \left(\frac{-\mathrm{u}^{2}}{2}\right)$ & $1 / 2 \sqrt{\pi}$ & 1 \\
\hline
\end{tabular}

Key: $\mathrm{R}_{\mathrm{k}}=$ Roughness and $\mathrm{d}_{\mathrm{k}}=$ variance 
Uka et. al., The Performance Of The Kernel Regression Model .....

The model for this study is expressed as:

We shall obtain equation (3) by replacing $\mathrm{Yi}=I G D P_{i}$ and $\mathrm{x}=V M S_{i}$ in equation (2)

$I G D P_{i}=\mathrm{m}\left(\mathrm{VMS}_{\mathrm{i}}\right)+\varepsilon_{\mathrm{i}}, \quad \mathrm{i}=1, \cdots, \mathrm{n}$

$\forall \mathrm{m}(\mathrm{VMS})=n^{-1} \sum \mathrm{Wn}_{\mathrm{i}}(\mathrm{VMS}) I G D P_{i}$

where IGDP represents Industrial growth and VMS represents volume of money supply.

\subsection{Data Presentation}

Table 2: Distribution of Industrial GDP and Volume of Money Supply in Nigeria from 2001 - 2016

\begin{tabular}{|c|c|c|}
\hline Years & $\begin{array}{l}\text { Industrial GDP } \\
\text { (Billion of Naira) }\end{array}$ & $\begin{array}{c}\text { Volume of Money Supply } \\
\text { (Billion of Naira) }\end{array}$ \\
\hline 2001 & 1874.08 & 816.70 \\
\hline 2002 & 2042.72 & 946.30 \\
\hline 2003 & 3037.71 & 1225.60 \\
\hline 2004 & 4610.08 & 1330.70 \\
\hline 2005 & 6094.89 & 1725.40 \\
\hline 2006 & 7488.74 & 2280.60 \\
\hline 2007 & 7975.50 & 3116.30 \\
\hline 2008 & 9719.51 & 4857.30 \\
\hline 2009 & 8071.07 & 5017.10 \\
\hline 2010 & 15194.56 & 5571.30 \\
\hline 2011 & 16263.08 & 6771.00 \\
\hline 2012 & 5825.63 & 7420.95 \\
\hline 2013 & 2642.89 & 7032.84 \\
\hline 2014 & 4600.55 & 6904.79 \\
\hline 2015 & 15073.79 & 7312.00 \\
\hline 2016 & 3012.59 & 9864.00 \\
\hline
\end{tabular}

Source: Central Bank of Nigeria Statistical Bulletin 2016.

\subsection{DATA ANALYSIS AND INTERPRETATION}

4.1 Assessing the impact of money supply on industrial Growth

We shall first model a linear regression model to assess the impact of the independent variable (volume of money supply) on the dependent variable (Industrial Growth).

4.1.1 Result of Linear Regression Analysis of industrial GDP (IGDP) on Volume of money supply (VMS)

Call:

$\operatorname{lm}($ formula $=$ IGDP $\sim$ VMS $)$

Residuals: 
International Journal of Advances in Scientific Research and Engineering (ijasre), Vol 4 (7), July - 2018

$\begin{array}{cllll}\text { Min } & \text { 1Q } & \text { Median } & \text { 3Q } & \text { Max } \\ -7044904 & -3103421 & -91448 & 1847801 & 7917416\end{array}$

Coefficients:

$$
\text { Estimate Std. Error t value } \operatorname{Pr}(>|t|)
$$

$\begin{array}{lllll}\text { (Intercept) } & 4598264.9 & 2209612.0 & 2.081 & 0.0563\end{array}$

$\begin{array}{lllll}\text { VMS } & 553.4 & 416.0 & 1.330 & 0.2047\end{array}$

Signif. codes: 0 ‘***' 0.001 '**' 0.01 '*' 0.05 ' ? 0.1 ' ' 1

Residual standard error: 4663000 on 14 degrees of freedom

Multiple R-squared: 0.1122, Adjusted R-squared: 0.04881

F-statistic: 1.77 on 1 and 14 DF, p-value: 0.2047

Source: R-console 3.32

\section{Interpretation}

The result of the linear regression analysis found residual standard error value of 4663000 , R-square value of 0.1122 , F-statistic of 1.77 and a p-value of 0.2047 . This result indicates a weak coefficient of determination value and implies that the model is inadequate for estimating industrial growth. Also, it was found that volume of money supply does not impact significantly on industrial growth since p-value of 0.2047 is greater than critical value of 0.05 , assuming $95 \%$ confidence level.

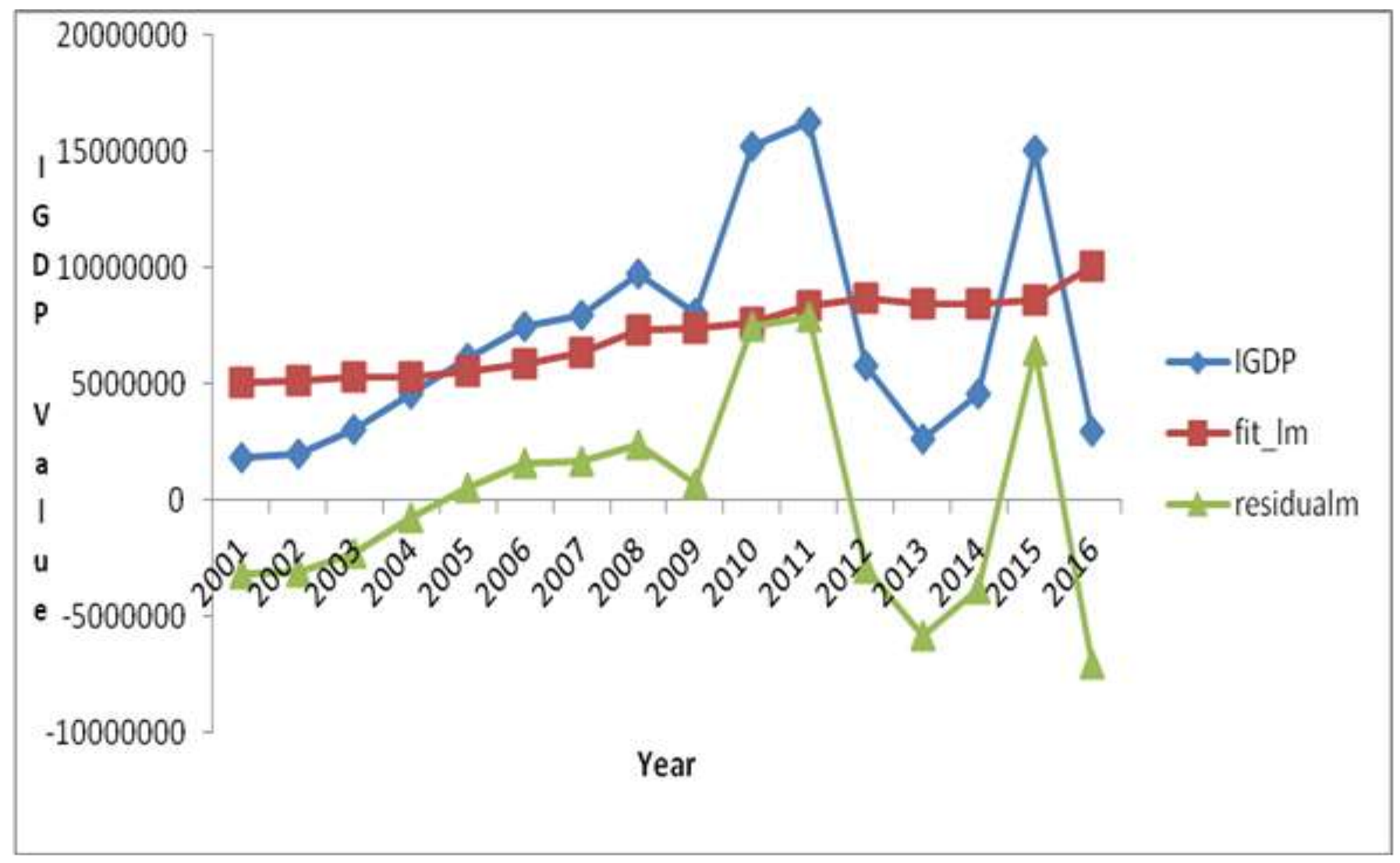

Figure 1: Graph showing Observed IGDP, fitted IGDP and Residual for the linear model

The result of figure 1 validates the result obtained above since the fitted value does not fluctuate like the observed value.

\subsubsection{Result of Kernel Linear Regression Analysis of industrial growth (IGDP) on Volume of money supply (VMS)}

Continuous Kernel Type: Second-Order Gaussian

No. Continuous Explanatory Vars.: 1

Regression Data (16 observations, 1 variable(s)):

$$
\text { VMS }
$$

Bandwidth(s): 1751.18

Regression Type: Local-Constant

Bandwidth Selection Method: Least Squares Cross-Validation

Formula: IGDP VMS

Bandwidth Type: Fixed 
Uka et. al., The Performance Of The Kernel Regression Model

Objective Function Value: 20475472 (achieved on multistart 1)

Kernel Regression Estimator: Local-Constant

Bandwidth Type: Fixed

Residual standard error: 3768207

R-squared: 0.5598028

Continuous Kernel Type: Second-Order Gaussian

\section{Kernel Regression Significance Test}

Type I Test with IID Bootstrap (399 replications, Pivot $=$ TRUE, joint $=$ FALSE $)$

Explanatory variables tested for significance: VMS (1) Individual Significance Tests

P Value: VMS $<2.22 \mathrm{e}-16 * * *$

Signif. Codes: 0 '***' 0.001 '**' 0.01 '*' 0.05 '.' 0.1 ' ' 1

\section{Interpretation}

The result of the kernel linear regression analysis found residual standard error value of 3768207, R-square value of 0.5598 , bandwidth of 1751.18 and a p-value of 0.00 . This result indicates a positive coefficient of determination value and implies that the model adequate for estimating unemployment rate. Also, it was found that volume of money supply impacts significantly on industrial growth using the smoothed model since p-value of 0.00 is less than critical value of 0.05 , assuming $95 \%$ confidence level. In addition, it was observed that the residual standard error value of 3768207 for the smoothed model is relatively more efficient than that of the linear model with a residual standard error value of 4663000 which was attributed to the performance of the kernel regression model.

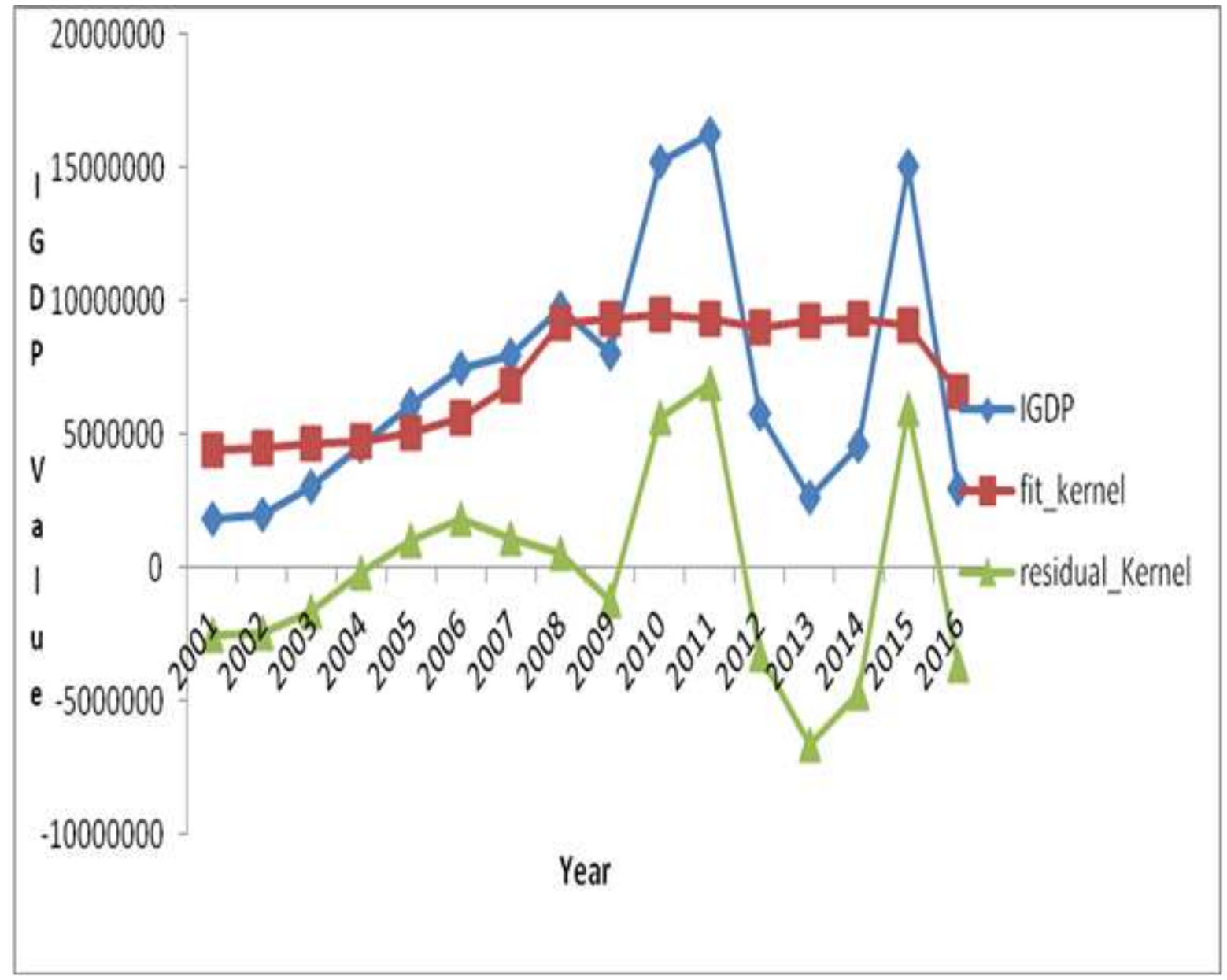

Figure 2: Graph showing Observed IGDP, fitted IGDP and Residual for the Kernel linear model

The result of figure 1 validates the result obtained in section 4.1.2 since the fitted value fluctuate like the observed value. 
International Journal of Advances in Scientific Research and Engineering (ijasre), Vol 4 (7), July - 2018

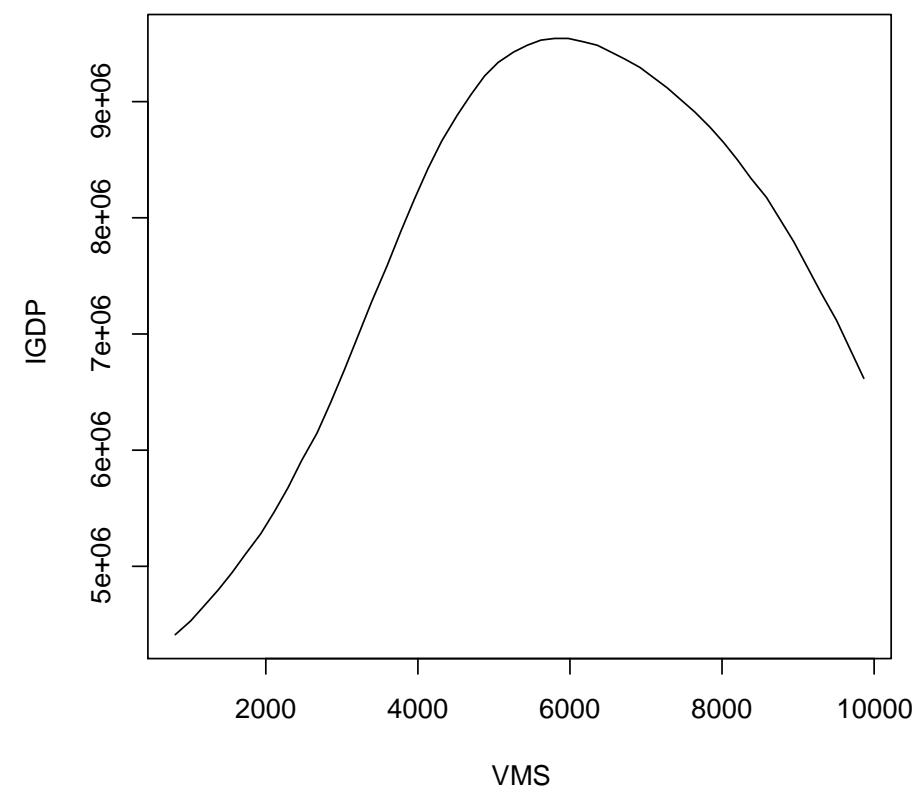

Figure 3: Graph showing industrial GDP against Volume of Money Supply

Table 3: Summary of Observed, fitted values and Residual for Linear Regression model and Kernel Linear Regression Model for estimating Industrial GDP

\begin{tabular}{|l|c|c|c|c|c|}
\hline Years & IGDP & fit_lm & Residua_lm & fit_kernel & Residual_Kernel \\
\hline $\mathbf{2 0 0 1}$ & 1874083 & 5050433 & -3176350 & 4410532 & -2536448.9 \\
\hline $\mathbf{2 0 0 2}$ & 2042716 & 5121828 & -3079112 & 4489760 & -2447044 \\
\hline $\mathbf{2 0 0 3}$ & 3037706 & 5276793 & -2239087 & 4678154 & -1640447.7 \\
\hline $\mathbf{2 0 0 4}$ & 4610084 & 5334906 & -724822 & 4755268 & -145184.4 \\
\hline $\mathbf{2 0 0 5}$ & 6094891 & 5552964 & 541926.5 & 5081467 & 1013423.9 \\
\hline $\mathbf{2 0 0 6}$ & 7488744 & 5860682 & 1628062 & 5660389 & 1828354.8 \\
\hline $\mathbf{2 0 0 7}$ & 7975498 & 6322812 & 1652686 & 6822767 & 1152730.8 \\
\hline $\mathbf{2 0 0 8}$ & 9719514 & 7286367 & 2433147 & 9201043 & 518471 \\
\hline $\mathbf{2 0 0 9}$ & 8071071 & 7374919 & 696152.3 & 9310739 & -1239667.7 \\
\hline $\mathbf{2 0 1 0}$ & 15194561 & 7681529 & 7513032 & 9522160 & 5672401.5 \\
\hline $\mathbf{2 0 1 1}$ & 16263084 & 8345668 & 7917416 & 9353089 & 6909995.2 \\
\hline $\mathbf{2 0 1 2}$ & 5825630 & 8705410 & -2879780 & 9045117 & -3219487.3 \\
\hline $\mathbf{2 0 1 3}$ & 2642890 & 8490672 & -5847782 & 9243745 & -6600854.7 \\
\hline $\mathbf{2 0 1 4}$ & 4600548 & 8419830 & -3819282 & 9299716 & -4699167.6 \\
\hline $\mathbf{2 0 1 5}$ & 15073782 & 8645084 & 6428698 & 9105313 & 5968469.1 \\
\hline $\mathbf{2 0 1 6}$ & 3012582 & 10057486 & -7044904 & 6616300 & -3603718.4 \\
\hline
\end{tabular}




\begin{tabular}{|c|c|c|c|c|}
\hline Model & Variables & R-square & P-value & $\begin{array}{c}\text { Residual Standard } \\
\text { Error }\end{array}$ \\
\hline Linear & IGDP|VMS & $11.2 \%$ & 0.205 & 4663000 \\
\hline Kernel & IGDP|VMS & $56.0 \%$ & $0.00^{*}$ & 3768207 \\
\hline
\end{tabular}

\subsection{CONCLUSION}

This study examined the performance of the kernel model over the linear regression model for a real life application in Nigeria. The kernel regression model is a nonparametric regression method that estimates the conditional expectation of a random variable with the sole objective of finding a non-linear relation between a pair of random variables. The linear and kernel model were used to assess the impact of volume of money supply in Nigeria on industrial growth in Nigeria.

Findings showed that there exist a weak positive coefficient of determination measure between volume of money supply and industrial growth which implies that the volume of money weakly explains the total amount of variation in industrial growth using the linear regression model while the kernel model found a strong positive coefficient of determination value which implies that the kernel model was adequate and far better than the linear model for estimating industrial growth in Nigeria.

Also, it was found that volume of money supply does not impact significantly on industrial growth in Nigeria using the linear model while it was found that volume of money impacts significantly on industrial growth using the kernel model.

Further findings showed that the residual standard error value for the smoothed model is relatively more efficient than that of the linear model which was attributed to the performance of the kernel regression model.

\section{REFERENCES}

1. Dauda, R. O. S. (2006). The Determinants of Manufacturing Sector Growth Performance in Nigeria. Nigerian Journal of Economic and Social Studies, Vol. 5.

2. Fashola, M. A. (2004). A Scheme for Nigeria's Optimal Industrial Development in Industrialization, Urbanization and Development in Nigeria (1950-1999), ed: M. O. A. Adejugbe, Concept Publications Limited.

3. Mishel, L. and Shierholz, H. (2011). Sustained, high joblessness causes lasting damage to wages, benefits, income, and wealth, economic policy institute. Briefing paper No 324. August 31.

4. Nadaraya, E. A. (1964). On estimating regression. Theory of Probability and its Application, 9:141-142.

5. Obioma, B. K., Uchenna, A.

6. N. and Kalu, O. U. (2015). The Effect of Industrial Development on Economic Growth: An Empirical Evidence in Nigeria 1973-2013. European Journal of Business and Social Sciences, 4(2): 127 - 140.

\section{APPENDIX}

Rcode for computing the least-squares cross-validated bandwidths for the local constant estimator (default) of the variable IGDP and VMS

$R>$ bw $<-$ npregbw(formula=IGDP $\sim \mathrm{VMS}$ )

$R>$ bw

Rcode for fitting the kernel model

We employ the bandwidths (bw) and fit the model and gradients

$R>$ bw $<-$ npregbw(formula $=$ IGDP $\sim$ VMS)

$R>$ kmodel $<-\operatorname{npreg}(\mathrm{bws}=\mathrm{bw}$, gradients $=$ true $)$

$R>$ summary(kmodel)

$R>$ npsigtest(model)

$R>$ model $=\operatorname{lm}(\mathrm{IGDP} \sim \mathrm{VMS})$ 